strata, and also birds. The finest piece of painting was a single fragment, which in style recalls the art of Palenque, discovered in the sixth stratum. A number of tiny bowls, of very rough ware, often in the form of birds or animals, were found in the middle strata. These may have been votive offerings, or, more probably, children's toys.

As regards the plates, tripod and plain (with a simple ring foot), the ware is thicker and coarser than that of the bowls, and the feet, where present, are of the cascabel pattern, hollow, and enclosing a small clay pellet which forms a rattle. The rims are usually surrounded with a band of painted design, based on textile art, or the 'twist-and-bud' pattern, often supplemented with a row of glyphs. The centre is usually occupied by a formal design (often cruciform), but sometimes by the figure of an animal or snake or human being.

Apart from fragments of metates and manos (the tripod slabs and rollers used in grinding maize), stone remains were remarkably few, and represented by only three spear-blades of flaked chert. Obsidian flakes and cores were found in quantities.

A remarkable bone pendant was discovered in the second stratum. This is formed from the ascending ramus of the right mandible of a human lower jaw. The condyles have been filed off, and just below the notch a hole has been pierced for suspension. The exterior surface is covered with relief carving, the main feature of which is four glyphs arranged in a square. This object, which is probably an amulet, is, I believe, unique.

Objects of worked shell are rare, and limited to a few beads. The most interesting is a large spiral shell, which had been rubbed down on two sides, so that the remaining portion represents the central longitudinal section. Small river-shells, some pierced for suspension, were found in quantities.

\title{
New Sundial in the Royal Botanic Gardens, Kew.
}

GOME months ago a beautiful pillar which had come from the old Kow Bridge, and had been presented to the Royal Gardens by Mr. George Hubbard, was set up in the grounds of Cambridge Cottage. Prof. Vernon Boys, having learned from

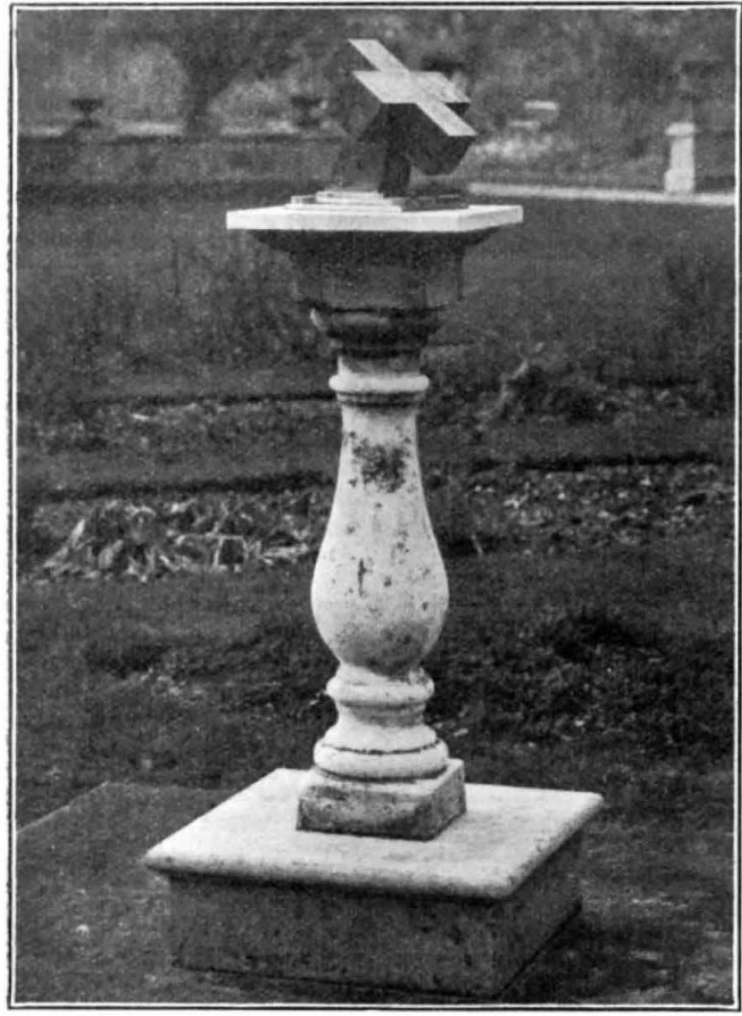

Fig. 1.-New sundial in the Royal Botanic Gardens, Kew.

the Director that a sundial was required to stand on this pillar, generously offered to provide one which would be worthy of the position. Prof. Boys has designed a dial and made it himself. It is now in place and can be seen and proved by the public (Fig. 1).

Nowadays a sundial is generally regarded as a mere ornament to a garden, and if it is in error by a few minutes nobody minds. After all, the dial gives local apparent time and it is too much trouble for most people to ascertain the correction necessary to obtain Greenwich mean time. Prof. Boys has no patience with such slackness. He has aimed at getting the time to the nearest minute. Not only is his dial made with the greatest precision; it carries an inscription on the southern or upper cube which

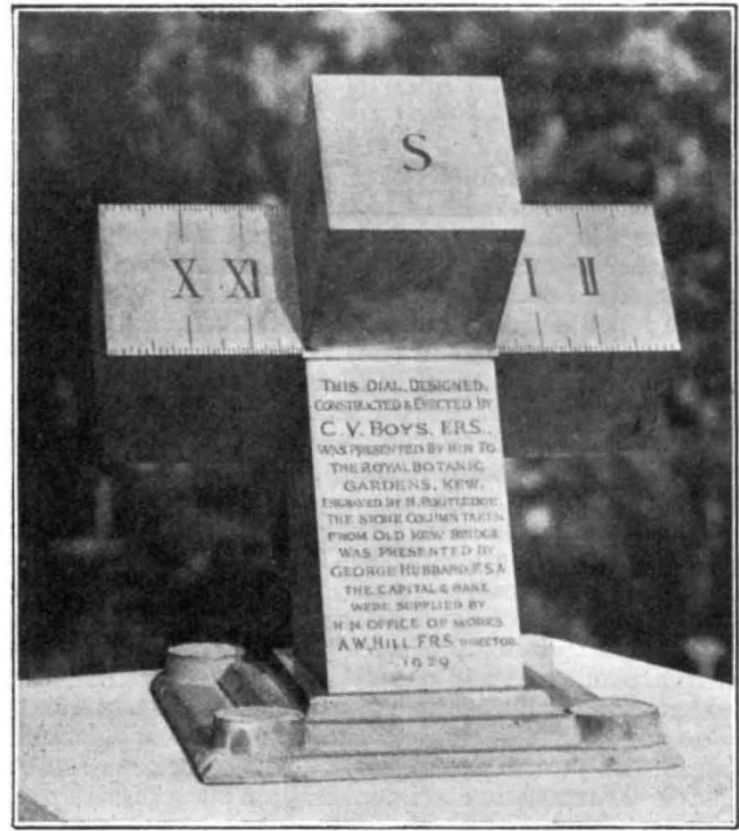

FIG. 2.-'Dial' of the Kew sundial.

gives in clear figures the correction to be applied to deduce Greenwich mean time from Kew apparent time on any given day of the year. This is contained in a table of 88 entries calculated from the equation of time of next year (a year half-way between two leap years), for each day, to which the time corresponding to the longitude of Kew has been (algebraically) added. Any member of the public by adding the correction of the actual day to the time shown by the sun, or subtracting as the case may be, will have Greenwich mean time. 
The dial itself is not of the conventional type (Fig. 2). In fact it is doubtful whether the word 'dial' is strictly appropriate. Perhaps we should say that there are six dials. Prof. Boys had adapted a design which is to be found occasionally in churchyards. The dial is built up with five blocks arranged in the form of a Greek cross. When the dial is in position the plane of the cross is parallel to the equator, so that the outer edges of the cubes which form the arms are parallel to the earth's axis. The shadows of these outer edges fall in succession on the adjacent arms of the cross. The graduations which serve for telling the time are along the edges. Gun-metal has been used for the cross and its stand. The central block is a cube; the other four blocks which form the arms of the cross are 3 in. long and $2 \frac{7}{8}$ in. wide. The accurate machining of these blocks is a necessity of the design.

The engraving was done for Prof. Boys by Mr. $H$. Routledge, who is the engraver responsible for the finest work on Admiralty charts. After the divisions and lettering had been engraved, each part of the dial was exposed to very dilute hydrogen sulphide and ammonia for about two minutes. The black was cleaned off the flat surfaces with Water-of-Ayr stone and the engraved work was left black. The effect is very pleasing.

The five blocks which form the dial are mounted on a trapezium-shaped support at the inclination appropriate for Kew. How the parts are held together is not apparent. The support is attached to the stone pedestal in a neat way. Four bolts are cemented into the pedestal. After the nuts were screwed on to these bolts, melted tin was poured into little pits surrounding the nuts and hides them from sight. No one will be tempted to unscrew the bolts and appropriate the sundial.

The precision with which a sundial can be used is limited by the lack of sharpness in the shadow of the gnomon. Theoretically, the width of the penumbra should be equivalent to two minutes on the time scale. It is found that time can be read to a minute on the new dial. Probably the reading corresponds fairly closely with the middle of the penumbra and is therefore in accordance with the intention of the designer. By a curious chance the sundial has been placed in the only part of the Royal Gardens from which a public clock is clearly visible. The clock of Kew Church can be seen over the wall of the Gardens and it will be possible to regulate the clock by direct comparisons with the dial.

It will be seen from Fig. 1 that the dial is well balanced on its pillar and looks handsome as well as businesslike.

The history of the dial and the stone column which supports it is engraved on the sloping face of the trapezium-shaped support and is as follows :

"This Dial, Designed, Constructed \& Erected by C. V. Boys, F.R.S., was presented by him to The Royal Botanic Gardens, Kew. Engraved by H. Routledge. The Stone Column taken from Old Kew Bridge was presented by George Hubbard, F.S.A., the capital and base were supplied by H.M. Office of Works. A. W. Hill, F.R.S., Director. 1929."

Visitors to the Gardens who are interested in sundials should remember to look at the dial which was put up by William IV. to commemorate Bradley's observations at Kew House. The pedestal of this sundial bears the King's monogram very skilfully carved. The dial itself was made by Tompion.

\section{Filterable Viruses. ${ }^{1}$}

$\mathrm{T}$ HE invisible multiplying bodies generally known as filterable viruses are among the most interesting things in biology to-day, partly because they are the cause of many diseases in animals and plants, and chiefly because they seem as if they might in the end prove to be some of the transitional forms between live and dead matter. Knowledge about them is moving so quickly that it is difficult to know at any moment where we are, and the compilation which Dr. E. B. McKinley has put together will be welcomed as a useful attempt to summarise all we know of them up to date.

Dr. McKinley deals rather fully with the virus diseases of man, animals, fowls, fishes, and insectsabout fifty in number - and has a chapter on typhus and the other Rickettsia diseases, in which the organisms are just visible. Under each disease he gives an adequate summary of the behaviour of the virus, and, going through them, one cannot but feel that we have to do with what is really a natural group of agencies, though they are distinguished from better known agencies, such as bacteria, mainly on the point of size.

These summaries necessarily contain only a selection of what has been said about each virus, and the selection of the compiler is naturally influenced by his point of view. Dr. McKinley writes mostly as a systematist and he nowhere notices Sanfelice's work on epitheliana contagiosum of fowls, his separation of a nuclo-proteid which would reproduce the disease on inoculation into a fresh animal and his fundamental suggestion that a virus might be a chemical substance which influenced cells in such a way that they produced more of it.

The account of the virus diseases of plants is far

1 "Filterable Viruses and Rickettsia Diseases." By E. B. McKinley. Philippine Journal of Science, vol. 39 , pp. 1-416, 70 plates; 1929. less satisfactory : it is not clear whether the author meant it to be as complete as that of the animal diseases or not: it certainly is not. This is rather unfortunate, for plants show clearly some important points which are not so plain in animals, as, for example, the possibility of a host containing large quantities of virus without showing any symptoms of disease, as potatoes often do. The modes of transmission in the plant diseases are also curious, for while some of them, for example, tomato mosaic, are easily conveyed by contact or inoculation, others, such as aster yellows, can be passed from one plant to another only by insects and artificial inoculation fails. The animal diseases such as yellow fever, which are normally conveyed by insects, can be transmitted equally well by a hypodermic syringe. It seems as likely that we shall get a just. view of what viruses really are from a study of those of plants as from those which affect animals : the Rous cancer virus and the bacteriophage are also very significant : both of them are dealt with by McKinley.

Another section discusses the vexed question of invisible forms of ordinary bacteria, for which there is a good deal of evidence not to be lightly dismissed, and finally the strange "inclusion bodies " are described and abundantly illustrated. These large intracellular, often intranuclear, objects are present in many, though not all, of the animal and plant diseases, and they have a characteristic appearance which may be put to useful purposes in diagnosis, for example in rabies. They may represent some form or stage of the virus itself, but they are more probably peculiar cell-reactions: their specificity recalls that of plant-galls, and contrasts strongly with the relative uniformity of the tissue reactions of animals to different bacillary parasites. 